\title{
The Effect of Nanosized Carbon Black on the Physical and Thermomechanical Properties of $\mathrm{Al}_{2} \mathrm{O}_{3}-\mathrm{SiC}-\mathrm{SiO}_{2}-\mathrm{C}$ Composite
}

\author{
Mohamad Hassan Amin, Mohsen Amin-Ebrahimabadi, and Mohamad Reza Rahimipour
}

Department of Ceramics, Materials and Energy Research Centre (MERC), Meshkin-Dasht Road, Karaj 3177983634, Iran

Correspondence should be addressed to Mohamad Hassan Amin, doctoramin@gmail.com

Received 24 September 2008; Accepted 22 January 2009

Recommended by Alan K. T. Lau

\begin{abstract}
The effects of using nanosized carbon black in the range of 0-10 weight percentages on the physical and thermomechanical properties of $\mathrm{Al}_{2} \mathrm{O}_{3}-\mathrm{SiC}-\mathrm{SiO}_{2}$-graphite refractory composites were investigated. Nanosized carbon black addition improved the relative heat resistance and oxidation resistance of composites. The bulk density of the composites is reduced with increasing carbon black (CB) content. Increase in CB content first causes an increase in the apparent porosity, but at more than $3 \mathrm{wt} \%$ amount of $\mathrm{CB}$, a decrease of apparent porosity was observed. The cold crushing strength (CCS) increased with increasing $\mathrm{CB}$ content in samples fired at $800^{\circ} \mathrm{C}$ and in samples fired at $1500^{\circ} \mathrm{C}$ when the content is increased to $3 \mathrm{wt} \%$, but the CCS decreased with increasing $\mathrm{CB}$ content in samples fired at $1500^{\circ} \mathrm{C}$ when the $\mathrm{CB}$ content was less than $3 \mathrm{wt} \%$. The composite without $\mathrm{CB}$ exhibits the highest value of CCS at firing temperature of $1500^{\circ} \mathrm{C}$.
\end{abstract}

Copyright (c) 2009 Mohamad Hassan Amin et al. This is an open access article distributed under the Creative Commons Attribution License, which permits unrestricted use, distribution, and reproduction in any medium, provided the original work is properly cited.

\section{Introduction}

$\mathrm{Al}_{2} \mathrm{O}_{3}-\mathrm{SiC}-\mathrm{SiO}_{2}$ refractory composites have been widely used as a castable refractory in several applications in the iron and steel making industry. However, $\mathrm{Al}_{2} \mathrm{O}_{3}$-based castables have poor resistance to corrosion (especially in a basic slag environment) and spalling [1]. The growing demand and application of these castable materials encourage researchers and producers to investigate their physical, chemical, and thermomechanical properties.

The successful development of oxide carbon bricks in the $1970 \mathrm{~s}$, by adding carbon to oxide brick formulations, suggested that introducing carbon (graphite) into current oxide based castables would give improved properties [1]. In recent years, one of the most significant trends in refractory technology has been associated to the development of carbon-containing refractory castables. $\mathrm{Al}_{2} \mathrm{O}_{3}-$ $\mathrm{SiC}-\mathrm{SiO}_{2}-\mathrm{C}$ refractory composites are commonly used in the iron and steel making industry, especially in blast furnace iron/slag runners. With the advent of quality steel making processes, it became essential to opt for good quality refractories, especially monolithic castables which were suitable in the presence of molten slag and metal [2]. The use of graphite as a carbon source has many advantages in refractory applications [3]. It has a high melting point and promotes the improvement of the corrosion resistance of the refractory, mainly due to its lower wettability by metal and slag. Thermal shock resistance of the refractory is improved due to the low thermal expansion, high thermal conductivity, and low modulus of elasticity promoted by the graphite addition. On the other hand, these composites have a few disadvantages, such as oxidation of graphite and reduction of fracture strength and Young's modulus because of the presence of graphite flakes.

Recent research has revealed that replacing graphite flakes with nanocarbon powder such as in situ formation of nanofibres in the matrix of C-containing refractories can markedly improve the refractories properties and performance $[4,5]$. In spite of these studies, the influence of nanosized carbon black on properties of $\mathrm{Al}_{2} \mathrm{O}_{3}-\mathrm{SiC}-\mathrm{SiO}_{2}-$ graphite refractory composites is not yet clearly understood. This will be addressed in the present paper by measuring behavior of a typical $\mathrm{Al}_{2} \mathrm{O}_{3}-\mathrm{SiC}-\mathrm{SiO}_{2}$-graphite castable. 


\section{Experimental Procedure}

Alumina-SiC-SiO 2 -graphite refractory composites were obtained from a mixture of tabular alumina grains (Alfa-tab30, Silkem, Slovenia), with grain sizes up to $5 \mathrm{~mm}$, reactive alumina (PFR 20, Pechiney, France), silicon carbide (EC6F220, Treibacher, Austria-Brazil), microsilica (971, Elkem Co., Norway). All composites contained $2 \mathrm{wt} \%$ natural Chinese flake graphite (Great Wall Group) with an average flake size of $100 \mu \mathrm{m}$, an ash content of $5 \mathrm{wt} \%$ and density of $2.26 \mathrm{gr} / \mathrm{cm}^{3}$. A modified Andreasen grain size distribution (Dinger and Funk) [6], with maximum grain size of $5 \mathrm{~mm}$ and modulus $n=0.8$, was used for all the composites and the tabular alumina fractions were varied to obtain the specified grain size distribution. The composite mixed with amounts of $0,1,2,3,4,5,6,7,8,9$, and $10 \mathrm{wt} \%$ nanoparticles of carbon black (CB), with average size about $20 \mathrm{~nm}$, and liquid phenolic Novalac resin was used as binder in amount of $0.1 \%$ weight also for all composites.

Raw materials were weighed (each batch $10 \mathrm{~kg}$ ) and then dry mixed for 4 minutes in a Hobart mixer. After water addition, wet mixing was continued for another 4 minutes. The mixture was poured into the moulds of $50 \mathrm{~mm} \times 50 \mathrm{~mm}$ $\times 50 \mathrm{~mm}$ without vibration. After demoulding, the samples were cured for 24 hours at room temperature and cured samples were dried at $110^{\circ} \mathrm{C} / 18 \mathrm{~h}$. Then, all compositions were heat-treated in a reducing atmosphere up to $1450^{\circ} \mathrm{C}$ for 5 hours to remove the volatile species and to minimize their influence.

Bulk density and apparent porosity of samples measured according to ASTM C20-97, and cold crushing strength (CCS) of the samples was measured according to ASTM C133-97.

Relative heat resistance was determined by the method according to [7]. In this method, prismatic samples are subjected to abrupt thermal cycling with heating to $850^{\circ} \mathrm{C}$ and cooling on water-cooled plate. After the chosen number of cycles, the samples are tested for bending strength. Relative heat resistance $R_{\text {rel }}$ is evaluated by the formula

$$
R_{\mathrm{rel}}=\left[\frac{\sigma_{F}^{3 C}\left(\sigma_{F}^{7 C}+0.1\right)}{\sigma_{F}}\right]^{1 / 2},
$$

where $\sigma_{F}$ is ultimate bending strength after gradual roasting at $850^{\circ} \mathrm{C}, \sigma_{F}^{3 C}$ is ultimate bending strength after three heating-cooling cycles, and $\sigma_{F}^{7 C}$ is ultimate bending strength after seven heating-cooling cycles. The values of $\sigma_{F}, \sigma_{F}^{3 C}$ and $\sigma_{F}^{7 C}$ were determined for three pairs of samples. Samples that withstood thermal cycling were tested for ultimate bending strength.

The samples were oxidized isothermally at $1500^{\circ} \mathrm{C}$ for 5 hours, in an electric furnace by natural convection of air and fraction of weight loss was calculated $(\mathrm{Ox} \%)$ according to the equation:

$$
\mathrm{Ox} \%=\frac{\mathrm{I} \cdot \mathrm{C}-\mathrm{R} \cdot \mathrm{C}}{\mathrm{I} \cdot \mathrm{C}} \times 100,
$$

where I.C is the initial weight of carbon before oxidation, and R.C is the weight of residual carbon after complete

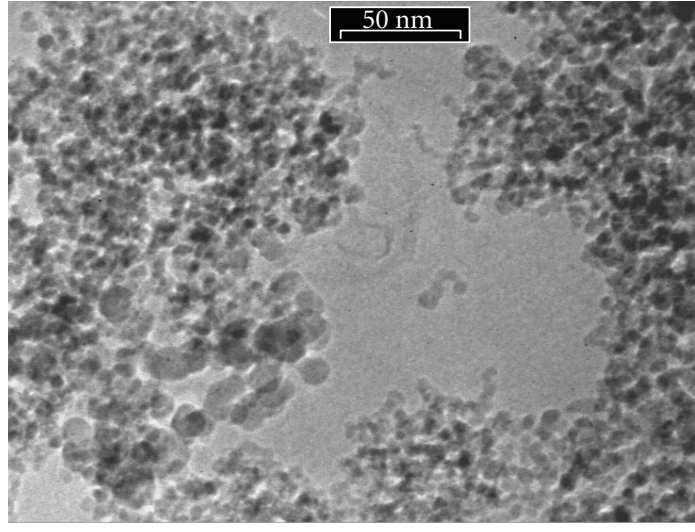

Figure 1: Typical electron micrographs of used CB.

oxidation. Carbon contents of samples were determined using the high-frequency combustion-infrared absorption method (CS-400, LECO). Observation of the microstructure was performed on polished faces using a scanning electron microscope or SEM (LEO-460) equipped with an energy dispersive spectroscopy (EDS) system (beryllium window). Transmission electron microscopy images were obtained using a Philips TEM operating at the voltage of $200 \mathrm{kV}$.

\section{Results and Discussion}

Figure 1 shows the transmission electron microscope (TEM) image of used CB. It is seen that nanoparticles are in spherical shape. Size measurement on the electron micrographs gave values in the range $5-30 \mathrm{~nm}$, with an average size around $20 \mathrm{~nm}$.

Figure 2 shows the dependence of the relative heat resistance of composites on amounts of $\mathrm{CB}$ as additive.

The results showed that the relative heat resistance of composites increased with the amount of carbon black. This can be correlated with the filling of pores and voids by $\mathrm{CB}$ particles beside gels; so that the structure of the castable is not compacted and stresses can be relaxed under the influence of heating cycles [7]. Castable without CB contains two sources of gel content, namely, alumina gel (the hydration product of hydratable alumina) and silica gel, which fills the pores and voids; however, castables containing $\mathrm{CB}$ show the higher relative heat resistance owing to the filling of pores and voids by $\mathrm{CB}$ particles beside gels, resulting in compact structure, because the large density difference between $C B$ and oxide raw materials. This result is attributed to the ability of the compressible carbon phase to absorb the expansion of alumina grains. The probability of any cracks formed fails to propagate because of the grain mismatch and consequent poor bonding between CB and ceramic phase [3].

The above claim was confirmed by investigating the microstructure investigation, as shown in Figure 3. Figure 3(a) exhibits an SEM photomicrograph of a composite without CB additive. Some minor phases can be observed between the alumina grains. These phases have a tendency to occupy of porous. Figure 4 shows the typical elemental 


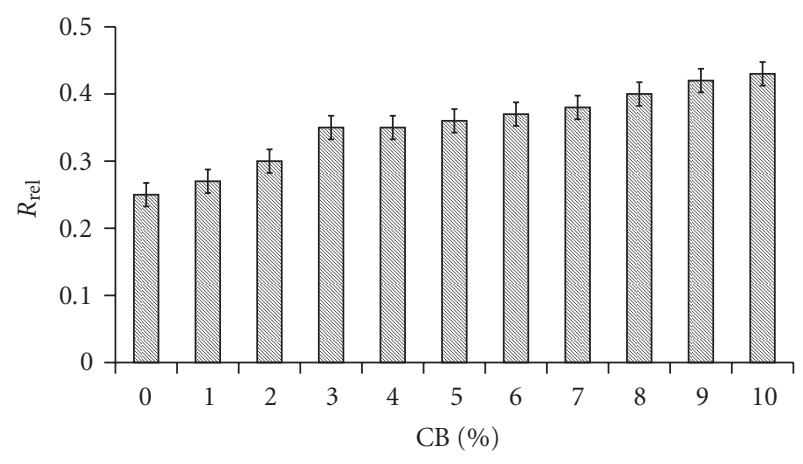

Figure 2: Dependence of the relative heat resistance of composites versus the amount of $\mathrm{CB}$. Bars refer to standard deviation.

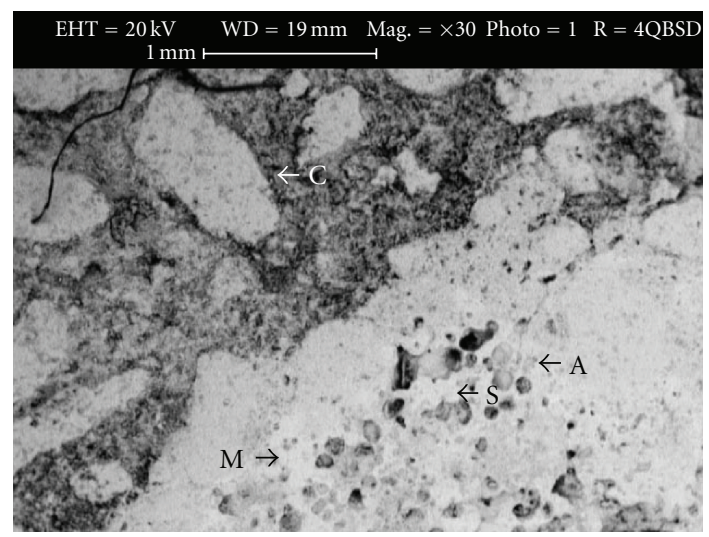

(a)

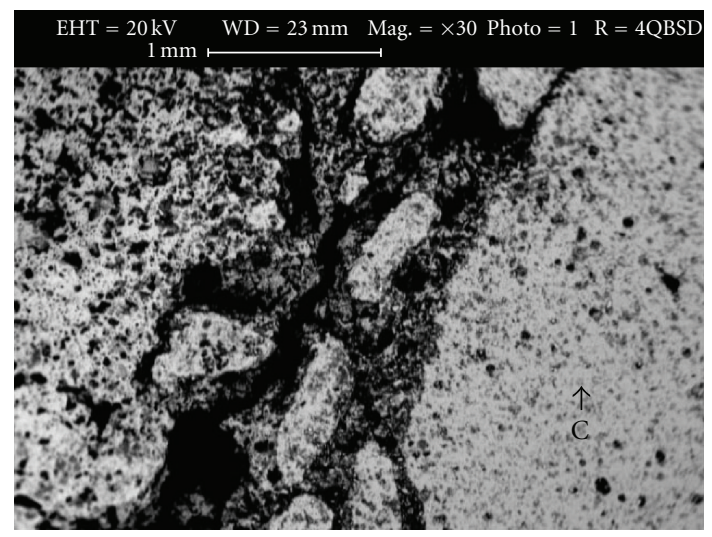

(b)

FIGURE 3: SEM micrographs of composites $(\times 30)$, (a) sample without $\mathrm{CB}$ and (b) sample containing $7 \mathrm{wt} \% \mathrm{CB}$.

analysis patterns of these phases. EDS analysis of phases A and $S$ confirms that these phases are based on alumina and silica, respectively, and phase $\mathrm{M}$ has similar stochiometric composition of mullite. The $\mathrm{Al}$ and $\mathrm{Si}$ elements are not observed in the X-ray spectroscopy of the phases $\mathrm{C}$ in Figures 3(a) and 3(b). It is concluded that these phases are just based on carbon.
Figure 5 shows the effect of CB content on the composite's apparent porosity and density. As can be seen, the bulk density of the composites is reduced with increasing $\mathrm{CB}$ content in samples, due to the lower density of the CB compared with the density of the other components.

Increase in $\mathrm{CB}$ content first causes an increase in the apparent porosity, but at larger amounts of CB, a decrease of apparent porosity was observed. The porosity is reduced by the influence of $\mathrm{CB}$ addition, which improves the packing efficiency. On the other hand, the porosity is increased by the oxidation of carbon and $\mathrm{CO}$ and $\mathrm{CO}_{2}$ gases exiting from the body in the low amount of $\mathrm{CB}$; but gas pressure of $\mathrm{CO}$ evolved during $\mathrm{C}$ oxidation prevents further oxidation [8]. This claim was confirmed by the measuring of the amount of residual carbon in samples on weight percent of $\mathrm{CB}$ as additive, as shown in Figure 6.

Figure 6 shows the oxidation percentage and mass $\%$ change of the residual carbon content (R.C) of composite with $\mathrm{CB}$ addition after heating at $1500^{\circ} \mathrm{C}$ for 5 hours in natural air. For the sample without $\mathrm{CB}$, the content graphite was almost completely oxidized; however, for the sample with $\mathrm{CB}$, a large unoxidized zone was still observed. The enhancement of gas pressure was considered to occur by the oxidation of carbon turning to $\mathrm{CO}$ and $\mathrm{CO}_{2}$. As a result, the pores were filled with condensed gases, and $\mathrm{O}_{2}$ would be expected to diffuse only a short distance. Consequently, carbon reacted with oxygen just at the original carbon site or the pores nearby and oxidation of carbon was reduced. It is considered that the enhancement of gas pressure can effectively suppress the diffusion of oxygen into the refractories, and the oxidation rate was decreased. This result confirmed that the addition of $\mathrm{CB}$ effectively improved the oxidation resistance of the refractories.

When used in blast furnace iron/slag runners, refractory composite castables are subjected to a high impact of iron/slag melt during tapping of blast furnace. The effect of this phenomenon on the refractory lining of runners is crushing of the lining, especially at the impact area of the main trough and the tilting runner. Thus knowledge of crushing behaviour is very important to prevent structural spalling and extensive cracking. To establish how the $\mathrm{CB}$ content influences the cold crushing strength (CCS) of refractory composite castables, CCS was measured after heat treatment at $800^{\circ} \mathrm{C}$ and $1500^{\circ} \mathrm{C}$.

Figure 7 shows the variation of CCS as a function of the $\mathrm{CB}$ content at different firing temperature. It can be seen that the CCS increased with increasing CB content in samples fired at $800^{\circ} \mathrm{C}$, but in samples fired at $1500^{\circ} \mathrm{C}$, an increase in $\mathrm{CB}$ content first causes a decrease in the CCS; however, when the content is increased to $3 \mathrm{wt} \%$, the CCS increases gradually as the $\mathrm{CB}$ content increases.

Ceramic matrix composites fracture occurs by one of the following mechanisms, depending on the pore structure: catastrophic fracture in dense and tough specimens, with the formation of one or several transcrystallite cracks; stepped fracture in specimens with a high concentration of microcracks and pores, with the formation of numerous transcrystallite cracks; gradual slow fracture in specimens 


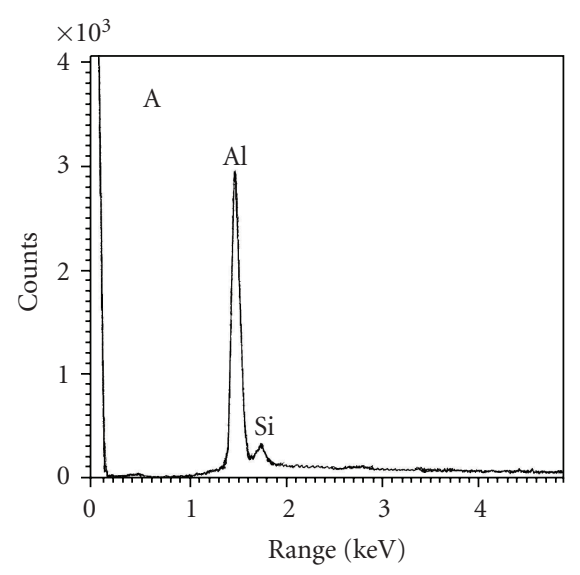

(a)

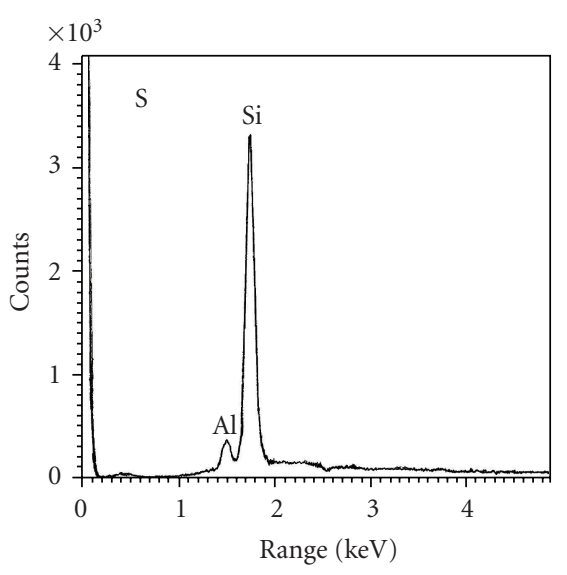

(b)

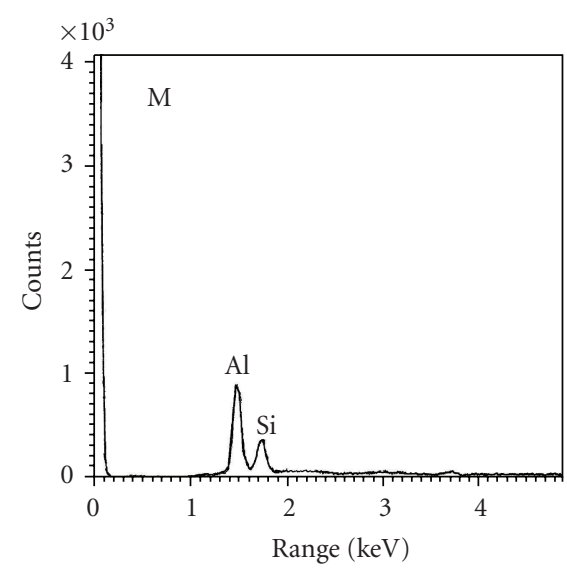

(c)

FIgURE 4: X-ray spectroscopy of the minor phases in Figure 2.

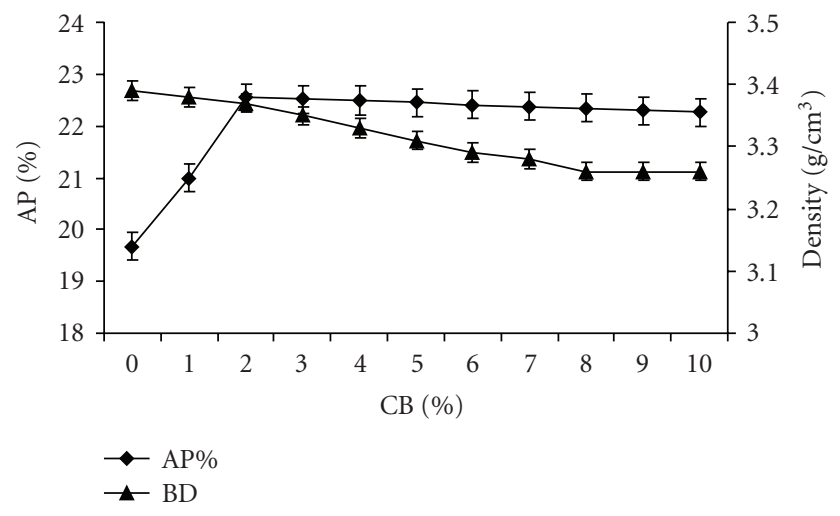

FIGURE 5: The effect of various amounts of CB on apparent porosity (AP) and bulk density (BD) of composite. Bars refer to standard deviation.

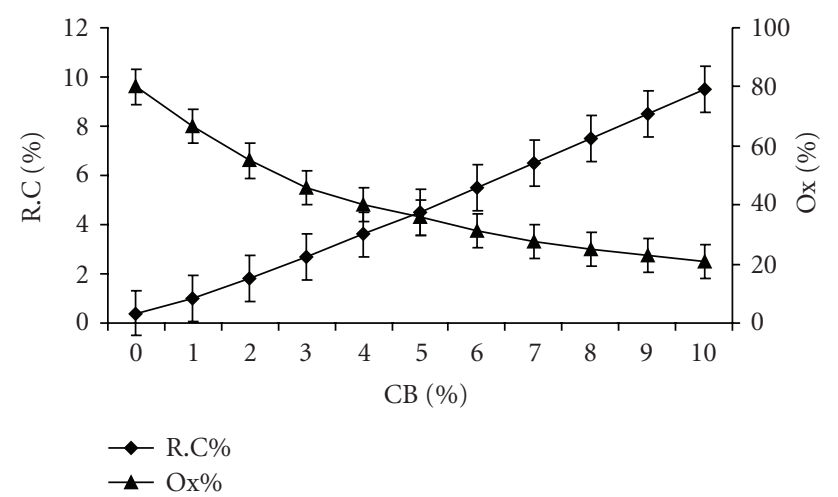

FIGURE 6: The residual carbon content (R.C) of composite (wt\%) and $\mathrm{Ox} \%$ versus $\mathrm{CB} \%$ as additive. Bars refer to standard deviation.

with low strength. The formation of cracks on the surface of the castables depends on their composition.

The increase in CCS in samples fired at $800^{\circ} \mathrm{C}$ with $\mathrm{CB} \%$ is almost linear, following a typical composite mixture rule. This can be correlated with the filling of pores and voids by

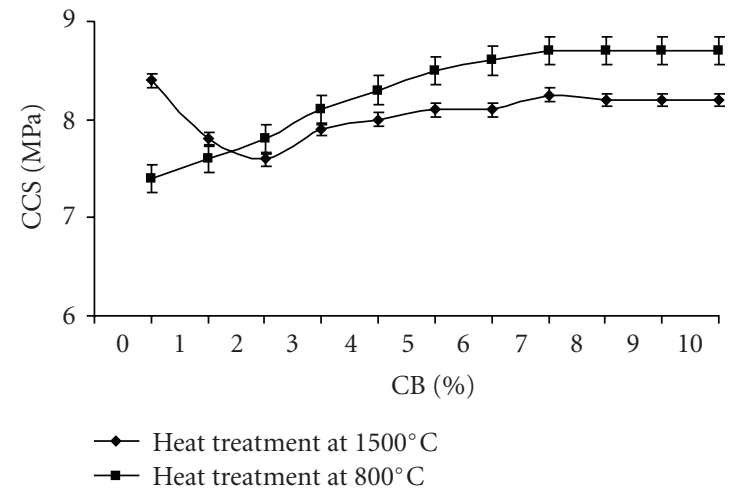

Figure 7: The CCS of composite versus CB\% as additive after heat treatment at $800^{\circ} \mathrm{C}$ and $1500^{\circ} \mathrm{C}$. Bars refer to standard deviation.

CB particle in castables containing CB (see Figure 3(b)). It seems that, in this situation, the ceramic matrix composites fracture occurs by gradual slow fracture in specimens with low strength. One of the reasons invoked to explain this effect is crack deflection along the nanosized carbon black particles, so the average stress intensity at its tip is reduced, because the stress is no longer always normal to the crack plane.

The composite without $\mathrm{CB}$ exhibits the highest value of CCS at firing temperature of $1500^{\circ} \mathrm{C}$ due to the formation of mullite phase (see Figure 3(a)) that causes the growth of elongated needle-shaped mullite crystals which strengthens the structure at high temperatures [9]. Because of the high reactivity of microsilica and reactive alumina, the formation of mullite phase occurs at temperatures above $1300^{\circ} \mathrm{C}$, and the porosity is reduced so there is a significant amount of increase in CCS compared to specimens fired at $800^{\circ} \mathrm{C}$.

Also, by comparing Figures 5 and 7, one can immediately see the correlation between the apparent porosity and CCS of specimens fired at $1500^{\circ} \mathrm{C}$. Therefore, the variation of the CCS values of specimens fired at $1500^{\circ} \mathrm{C}$ can also be represented as function of the apparent porosity. Increase 
in $\mathrm{CB}$ content of specimens fired at $1500^{\circ} \mathrm{C}$, first causes an increase in the apparent porosity and, as a result, the CCS value decreased because fracture occurs by stepped fracture mechanism, with the formation of numerous transcrystallite cracks. But at a larger amount of CB, the CCS decreases with the increasing of $\mathrm{CB} \%$. The reason for this variation of the CCS values can be attributed to the decrease of porosity. Pores are usually quite deleterious to the strength of ceramics not only because they reduce the cross-sectional area over which the load is applied, but more importantly because they act as stress concentrators. Typically the strength and porosity have been related by following empirical relationship:

$$
\sigma_{p}=\sigma_{0} e^{-B P}
$$

where $P, \sigma_{p}$, and $\sigma_{0}$ are, respectively, the volume fraction porosity and the strength of the specimen with and without porosity; $B$ is a constant that depends on the distribution and morphology of the pores [10].

\section{Conclusions}

Based on the above results, the following conclusions were drawn when nanosized carbon black was added as an additive to the $\mathrm{Al}_{2} \mathrm{O}_{3}-\mathrm{SiC}-\mathrm{SiO}_{2}-\mathrm{C}$ refractory composites.

(1) The relative heat resistance of composites increased with the amount of carbon black because in the presence of $\mathrm{CB}$, the pores and voids were filled by $\mathrm{CB}$ particles beside gels, so that the structure of the castable is not compacted and stresses can be relaxed under the influence of heating cycles.

(2) The bulk density of the composites is reduced with increasing $\mathrm{CB}$ content in samples due to the lower density of the $\mathrm{CB}$ compared with the density of the other components.

(3) Increase in CB content first causes an increase in the apparent porosity, because of oxidation of carbon and exiting of $\mathrm{CO}$ and $\mathrm{CO}_{2}$ gases from the body. At more than $3 \mathrm{wt} \%$ amount of $\mathrm{CB}$, a decrease of apparent porosity was observed, because the addition of nanosized carbon black improves the oxidation resistance of $\mathrm{Al}_{2} \mathrm{O}_{3}-\mathrm{SiC}-\mathrm{SiO}_{2}-\mathrm{C}$ refractory composites, and the pores were filled with $\mathrm{CB}$.

(4) The addition of CB effectively improved the oxidation resistance of the refractories, because $\mathrm{CB}$ plays a role as antioxidant.

(5) The CCS increased with increasing CB content in samples fired at $800^{\circ} \mathrm{C}$ and in samples fired at $1500^{\circ} \mathrm{C}$ when the content is increased to $3 \mathrm{wt} \%$, because the crack deflected along the nanosized carbon black particles, so the average stress intensity at its tip is reduced.

(6) The composite without $\mathrm{CB}$ exhibits the highest value of CCS at firing temperature of $1500^{\circ} \mathrm{C}$, due to the formation of mullite phase that causes the growth of elongated needle-shaped mullite crystals which strengthens the structure at high temperatures.
(7) The CCS decreased with increasing CB content in samples fired at $1500^{\circ} \mathrm{C}$ when the $\mathrm{CB}$ content was less than $3 \mathrm{wt} \%$, the reason for this variation of the CCS values can be attributed to the increasing of porosity.

\section{References}

[1] S. Zhang and W. E. Lee, "Carbon containing castables: current status and future prospects," British Ceramic Transactions, vol. 101, no. 1, pp. 1-8, 2002.

[2] S. Mukhopadhyay and P. K. Das Poddar, "Effect of preformed and in situ spinels on microstructure and properties of a low cement refractory castable," Ceramics International, vol. 30, no. 3, pp. 369-380, 2004.

[3] E. M. M. Ewais, "Carbon based refractories," Journal of the Ceramic Society of Japan, vol. 112, no. 1310, pp. 517-532, 2004.

[4] S. Tamura, T. Ochiai, S. Takanaga, T. Kanai, and H. Nakamura, "Nano-tech refractories-1. The development of the nano structural matrix," in Proceedings of the Unified International Technical Conference on Refractories (UNITECR '03), pp. 517520, Kyoto, Japan, October 2003.

[5] N. Kido, K. Yamamoto, M. Kamiide, et al., "Carbon nanofiber-a new trial for magnesia based bricks," in Proceedings of the Unified International Technical Conference on Refractories (UNITECR '03), pp. 264-267, Kyoto, Japan, October 2003.

[6] J. E. Funk and D. R. Dinger, "Particle size control for highsolids castable refractories," American Ceramic Society Bulletin, vol. 73, no. 10, pp. 66-69, 1994.

[7] N. M. Khalil, "Heat resistance and thermomechanical behaviour of ultralow and zero cement castables," British Ceramic Transactions, vol. 103, no. 1, pp. 37-41, 2004.

[8] A. Yamaguchi, "Affects of oxygen and nitrogen partial pressure on stability of metal, carbide, nitride, and oxide in carboncontaining refractories," Taikabutsu Overseas, vol. 7, no. 1, pp. 4-13, 1987.

[9] M. F. M. Zawrah and N. M. Khalil, "Effect of mullite formation on properties of refractory castables," Ceramics International, vol. 27, no. 6, pp. 689-694, 2001.

[10] M. Barsoum, Fundamentals of Ceramics, McGraw-Hill, New York, NY, USA, 1997. 

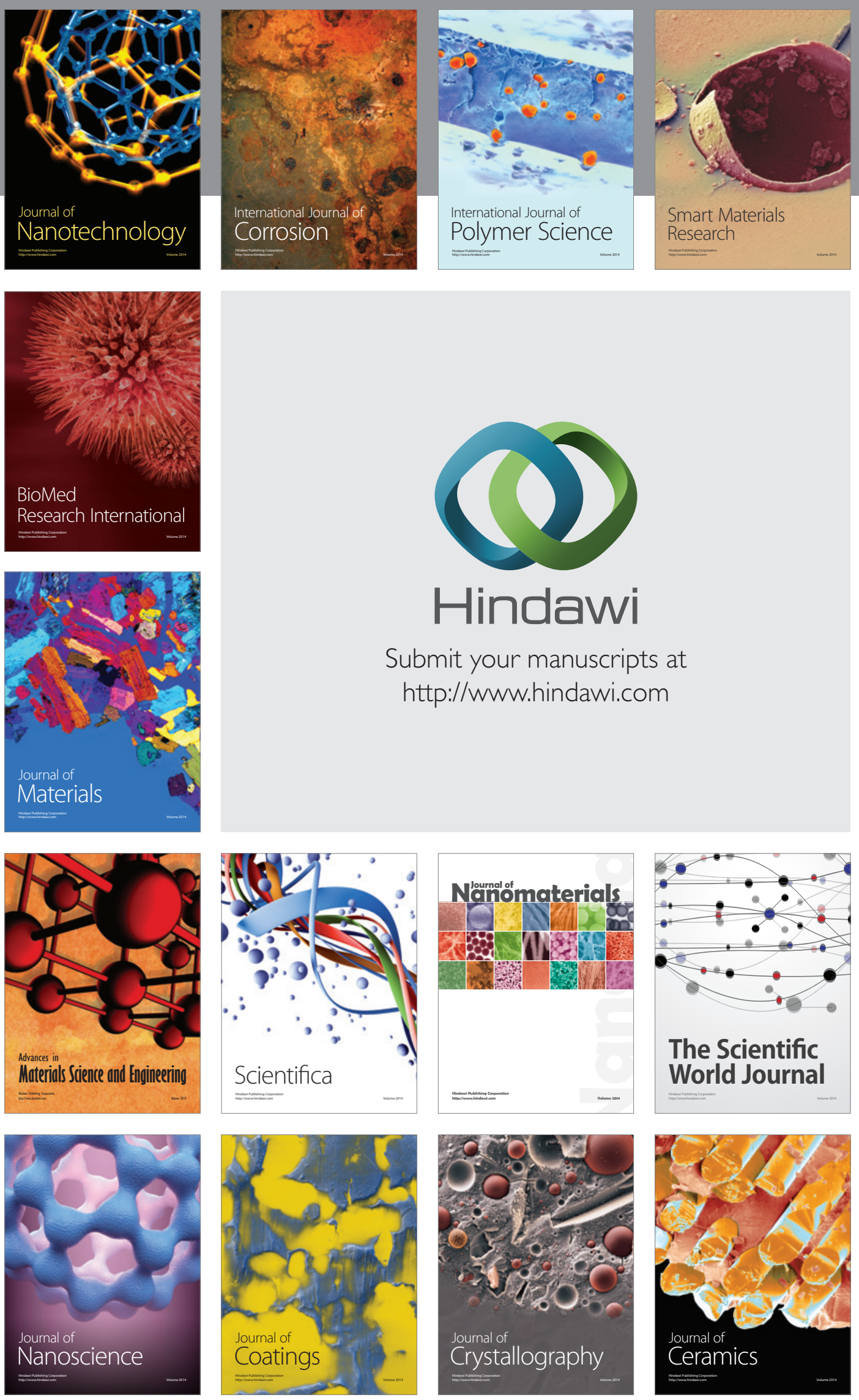

The Scientific World Journal

Submit your manuscripts at

http://www.hindawi.com

\section{World Journal}

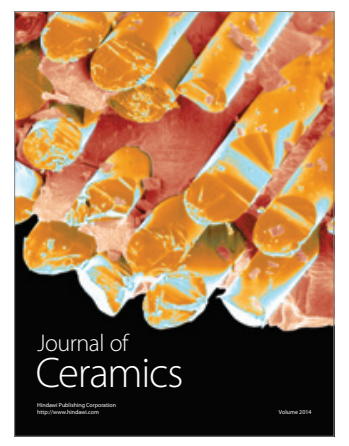

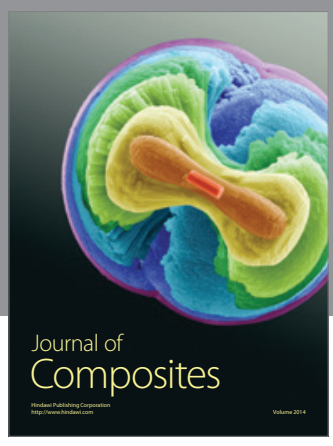
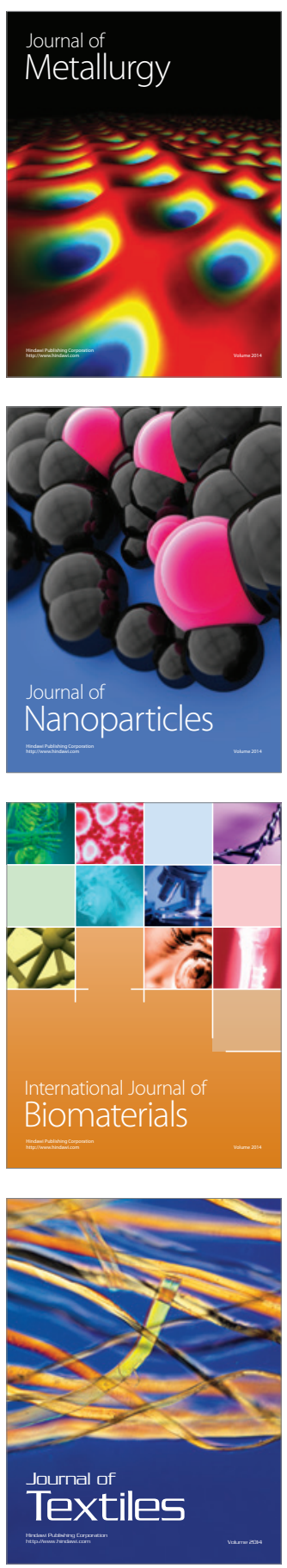